\title{
Artigos
}

\section{O chinelo rosa: Corpo e gênero na educação infantil}

Resumo: Trata-se do relato de uma pesquisa realizada em uma creche pública localizada no município de Porto Alegre-RS. Tal pesquisa foi realizada em uma abordagem qualitativa numa perspectiva cultural dos conceitos de corpo e gênero, com delineamento de estudo de caso. As análises estão ancoradas nesta perspectiva, a partir da reflexão sobre cenas observadas e selecionadas na rotina de sala de uma turma de Maternal 2. Os resultados obtidos apontam que as representações dos marcadores de gênero atribuídos ao feminino e masculino em nossa sociedade se entrecruzam com o pedagógico, impedindo em alguns momentos as crianças de participar das atividades, como na exploração de materiais de cunho artístico, e em outros, impelindo suas participações, como no exemplo das fantasias. Pretende-se assim, que os apontamentos feitos com a pesquisa possam contribuir para a reflexão sobre as conexões entre corpo e gênero na educação infantil, e a atuação docente.

Palavras-chave: Corpo; Gênero; Infância; Educação Infantil.

\section{Pink slipper: Body and gender in early children education}

\begin{abstract}
This is the report of a survey conducted in a public day care center in the municipality of Porto Alegre-RS. This research was conducted in a qualitative approach in a cultural perspective of the body and gender concepts with case study design. Analyses are anchored in this perspective, from the reflection of scenes observed and selected in the routine of a group of Maternal room 2. The results indicate that the representations of gender markers attributed to the female and male in our society are interwoven with the pedagogical, preventing at times the children to participate in activities such as the exploration of artistic imprint materials, and others, urging their participation, as in the example of costumes. It is thus intended that the notes made with the research can contribute to the reflection on the connections between body and gender in early childhood education, and teaching practice.
\end{abstract}

Keywords: Body; Genre; Childhood; Children Education.

'Pedagoga e professora de educação infantil. E-mail: krug.camila@gmail.com

2 Doutora em Educação e professora associada da Faculdade de Educação da Universidade Federal do Rio Grande do Sul.

Membro do Grupo de Estudos de Educação e Relações de Gênero (GEERGE-UFRGS).E-mail: rosangelarsoares@gmail.com 
ste artigo constitui-se como parte de uma pesquisa realizada em 2014 e já concluída no período de agosto à outubro do referido ano, em uma turma de Maternal II, de uma escola de educação infantil, na cidade de Porto Alegre e que atende crianças de 0 a 5 anos de idade no período integral. Trata-se de uma pesquisa com abordagem qualitativa numa perspectiva cultural que utiliza os conceitos de corpo e gênero.

$\mathrm{Na}$ presente pesquisa buscou-se analisar o gênero e o corpo e suas conexões com o pedagógico na educação infantil, nessa turma de Maternal II, composta por 18 crianças, sendo 11 meninos e 8 meninas, de 3 a 4 anos, que foram participantes desta pesquisa. A instituição onde a pesquisa foi realizada é uma escola de educação infantil pública, que atende crianças de 0 a 5 anos de idade, e está localizada no município de Porto Alegre. Atualmente atende 130 crianças em sua maioria pertencentes a classe média.

A busca e o interesse pela temática sobre corpo e gênero fazem parte de nossa vivência. Em parceria com mais duas graduandas da pedagogia, desenvolvemos a Ação de Extensão, - intitulada Educação em saúde e formação de professores: o corpo sobre múltiplos olhares - onde foram realizadas algumas pesquisas teóricas sobre a temática do corpo e do gênero. Tais estudos incitaram a aprofundar as temáticas citadas na perspectiva cultural, pois o corpo e o gênero nessa perspectiva estão socialmente vinculados a definições de masculino e feminino que vão além do biológico, associados aos comportamentos sociais do indivíduo, pois como afirma Goellner (2003, p.28) “um corpo não é apenas um corpo. É também o seu entorno". O corpo na educação infantil é especialmente demarcado por vestimentas e entornos relacionados às masculinidades e feminilidades presentes em nossa cultura, associados, como é possível observar na turma pesquisada, ao que parece ser comum nessa faixa etária, a princesas, príncipes e super-heróis.

Delimitamos o problema de pesquisa com os seguintes questionamentos: Como se dão as relações de gênero em uma turma de Maternal II, de uma escola de educação infantil pública, na cidade de Porto Alegre? Quais as conexões entre gênero e corpo durante as atividades da rotina da turma? 
Por intermédio de observações, essas questões foram problematizadas apontando como as relações de gênero e corpo, operam na turma de Maternal II, na educação infantil, visando compreender as conexões entre essas relações e as atividades pedagógicas. Buscou-se ainda, elencar algumas possibilidades de atuação do/a professor/a frente as situações envolvendo questões de corpo e gênero.

A escolha pela pesquisa qualitativa, relaciona-se especificamente, segundo Ludke e André (1986), por ela ter dentre outros fatores, o pesquisador como instrumento. Assim, pelas cenas apresentadas, procuramos analisar as situações ocorridas na rotina da turma escolhida, elencando algumas possibilidades de ação frente as questões de gênero. Ainda, segundo Minayo (1999) a pesquisa qualitativa não busca indicar o certo ou errado, tão pouco esta pesquisa teve intuito de apresentar formas corretas ou erradas sobre as atuações frente as questões de gênero, tanto das crianças, quanto do adulto, mas sim promover uma discussão em uma perspectiva cultural sobre essa temática com base nas cenas observadas.

Ludke e André (1986, p. 17) afirmam que: “o caso pode ser similar a outros, mas ao mesmo tempo é distinto, pois tem um interesse próprio, singular.” Isto é, a delimitação do tema a ser pesquisado, como estudo de caso, surgiu de acontecimentos que inquietavam especificamente nesta turma de Maternal II. As crianças vivenciavam e se posicionavam na rotina sobre o que é dito como masculino e feminino na nossa cultura, demonstrando com isso, a fixidez das questões sociais de gênero. Isto aconteceu com mais de uma criança, em diversas situações como a que intitula o trabalho, chinelo rosa ${ }^{3}$. Além destes, o interesse pela temática de gênero e corpo, aliado ao trabalho realizado ao longo do projeto de extensão foram motivadores para a realização da pesquisa.

Por intermédio da observação, foram feitas anotações no diário de classe como forma de registros das cenas. Delimitando os caminhos pelas questões que conduziram a pesquisa, isto é, quando o corpo e gênero se conectam com o pedagógico, foram selecionadas 4 cenas, entre agosto e outubro, para análise. Para a escolha das cenas, o critério foi em quais as relações de gênero pareciam mais evidentes, durante o período de observação.

As duas primeiras, foram atividades realizadas com as crianças dispostas em grupos. Tal forma de organização é a que habitualmente a turma realiza suas atividades. Em nenhum momento, foi definido pela professora a disposição das crianças nos grupos, elas escolhiam seus pares aleatoriamente, por afinidades. Na terceira e na quarta cena analisada, as crianças estavam organizadas de outras formas, com mais liberdade de movimentação. Tais cenas delimitaram duas categorias para análise na pesquisa,

\footnotetext{
3 Um dos meninos da turma molhou suas roupas e tênis, sendo necessário a troca das mesmas. Como em seus pertences não havia outro calçado, a professora alcançou um chinelo rosa a criança, que fica de reserva na instituição para momentos como o relatado. O menino começou a chorar e gritar, negando-se a colocá-lo. Então depois de muita conversa e ele foi acalmando-se. A professora explicou-lhe que era necessário calçar os chinelos para que pudesse levantar-se da cadeira e participar das atividades propostas, pois iriamos nos deslocar pela instituição, além disso, era um dia frio para permanecer descalço; no entanto, ele preferiu ficar sentado sem sair do lugar do que colocar "chinelo de menina", tal como dito por ele. Esta é uma das situações ocorridas na sala do Maternal II, onde questões de gênero interferiram nas escolhas e ações das crianças, acabando por vezes em intervir nos planejamentos para a turma.
} 
intituladas: Quando o rosa vira vermelho - que apresenta a observação de situações nas quais as crianças utilizam a troca de cor rosa pela vermelha para manipulação do material, e a segunda categoria: borramentos das fronteiras de gêneros, quando nas atividades é perceptível no grupo que há um escape frente as fronteiras de gênero apresentadas durante a pesquisa.

Ao refletir sobre tais questões, quatro fatores se relacionaram nas cenas: a educação infantil; a infância; o corpo e o gênero numa perspectiva cultural. Assim, é relevante referenciá-los a fim de contribuir num âmbito mais teórico a compreender as reações apresentadas nas observações feitas durante a pesquisa.

\section{Educação Infantil e Infância}

Segundo a LDB Lei $\mathrm{n}^{\circ}$ 12.796, de 2013 art.29 a finalidade da educação infantil é o "desenvolvimento integral da criança de até 5 anos, em seus aspectos físico, psicológico, intelectual e social, complementando a ação da família e da comunidade" (BRASIL, 2013). Assim, ao falar da educação nas creches, reportamos a um ambiente de formação de indivíduos, de experimentação e exploração de vivências, que são permeadas pelas influências sociais e familiares que a criança recebe desde o seu nascimento, e que vão se modificando ou consolidando pelas relações estabelecidas no espaço da creche, com seus pares, professores, e outros funcionários do local.

A preocupação com esta modalidade tem ganhado maior destaque em nossa sociedade ao longo da história, com as mudanças sociais ocorridas nas famílias, como a inserção da mulher no mercado de trabalho e com estudiosos que visam compreender e estudar as demandas da educação infantil, tal como a autora Cerisara (1999) que explica sobre a finalidades do trabalho realizado com as crianças:

é preciso ter claro que o trabalho junto às crianças em creches e pré-escolas não se
reduz ao ensino de conteúdos ou disciplinas, ou de conteúdos escolares que reduzem e
fragmentam o conhecimento, mas implica trabalhar com as crianças pequenas em
diferentes contextos educativos, envolvendo todos os processos de constituição da
criança em suas dimensões intelectuais, sociais, emocionais, expressivas,
culturais,interacionais. (CERISARA, 1999, p.16)

Conjecturando a realidade atual, a criação da Lei no 12.796, de 4 de Abril de 2013 art.4, determinando "a educação básica obrigatória e gratuita dos 4 (quatro) aos 17 (dezessete) anos de idade" (BRASIL, 2013), que visa garantir o direito das crianças pequenas em estarem na escola, ampliou nesta perspectiva, o olhar social para a faixa etária atendida na educação infantil, tendo-se a necessidade da criação de novas instituições e/ou ampliação de espaços físicos específicos para atender o público em questão, demonstrando conforme as Diretrizes Curriculares Nacionais da Educação Básica (2013, p.39) uma mudança de perpectiva quanto aos sujeitos inseridos na educação infantil, considerando estes como: "sujeitos do processo educativo dessa etapa da Educação Básica" e que devem ter "oportunidade de se 
sentirem acolhidos, amparados e respeitados pela escola e pelos profissionais da educação, com base nos princípios da individualidade, igualdade, liberdade, diversidade e pluralidade."

A autora Bujes (2001, p.20) afirma que "a experiência que a criança vive na escola infantil é muito completa e complexa. Nela a criança desenvolve modos de pensar, mas também se torna um ser que sente de uma determinada maneira." $\mathrm{Na}$ educação infantil, qualquer assunto pode virar um tema, um projeto, que irá nortear o trabalho pedagógico com as crianças, e contribuir no seu desenvolvimento. Preferencialmente, os assuntos abordados devem surgir da curiosidade delas, ou da observação do professor frente as necessidades de um grupo.

A realidade cultural onde o sujeito nasce e se desenvolve, relacionada ao contexto histórico social, é o que precisamos observar quando queremos compreender as crianças que encontramos nos espaços escolares. Tais observações abrangem, também, as entrevistas realizadas com seus responsáveis.

Segundo Barbosa e Horn (2008, p.28) isso explica os modos como as crianças vivem suas infâncias, sendo entendidos "como construções socioculturais que diferem profundamente a partir do modo como as crianças se inserem no mundo". De modo que, as infâncias encontradas na educação infantil hoje, não são mais vinculadas somente a um indivíduo e seu processo de maturação ${ }^{4}$, mas também as influências sociais que recebe, seja dos adultos com quem convive, ou de seus pares. Corsaro (2009,p.31) define a cultura de pares "como um conjunto estável de atividades ou rotinas, artefatos, valores e interesses que as crianças produzem e compartilham na interação com seus pares". Pares que possuem a mesma faixa etária, seja aqueles as quais convivem dentro ou fora da escola.

Na realidade brasileira atual, como ressaltado por Guizzo, Felipe e Beck (2013, p.18) as infâncias: “[...] são vividas de zero aos doze anos incompletos, conforme a lei delega, de modos muito distintos e variados." Não há uma regra, uma fórmula para todos. As infâncias de hoje, em referência ao que dizem as autoras, contestam com o que historicamente tem sido construído como verdade para elas.

Contudo, pode se dizer que os modos de viver a infância estão permeados de representações sociais, o que denota como afirma Corsaro (2009, p.31): “[...] que as crianças não apenas internalizam a cultura, mas contribuem ativamente para a produção e a mudança cultural.” Assim sendo, em cada novo tempo, temos uma nova cultura, e novas formas de ser criança e de viver a infância, que são repassadas a cada geração.

\section{Corpo e Gênero}

Nessa perspectiva, as corporeidades infantis atuais estão permeadas por representações de uma sociedade, onde o corpo tem ganhado centralidade, como Meyer e Soares afirmam:

${ }^{4}$ Ver em LOPES, Jader Jane Moreira; VASCONCELLOS, Tânia de. Geografia da infância: territorialidades infantis. Currículo sem fronteiras, v.6, n.1, p. $103-107$, Jan/ Jun. 2006. 
Vivemos um tempo em que o corpo é exaustivamente falado, invadido, investigado e ressignificado: medicina, engenharia genética, tecnobiomedicina, psicologia, enfermagem, nutrição, direito, biologia, educação física, pedagogia, história, antropologia e sociologia, são apenas algumas das áreas que imbricadas e sobrepostas, têm interferido e redefinido com aquilo que chamamos de "nosso corpo". (MEYER e SOARES, 2013, p. 6)

Assim o olhar sobre nossos corpos em âmbito cultural é cada vez mais intenso, consequentemente, o olhar sobre o corpo da criança também. O indivíduo hoje é definido pelo seu corpo, ao qual são atribuídos diversos significados, que se referem desde a alimentação do sujeito, sua forma física, vestimentas utilizadas, as estéticas investidas como intervenções cirúrgicas e tratamentos cosméticos, e formas de se portar e de comportar com seu corpo.

As representações nos múltiplos sistemas de significação, estão implicadas no processo de construção de identidade, pois segundo segundo Hall (2000, p. 112): “[...] as identidades são posições que o sujeito é obrigado a assumir [...] são representações ". A identidade social do sujeito, é muito atribuída ao seu corpo, que precisa ser valorizado e modificado para se enquadrar na representação daquilo que os outros esperam, o, que geralmente está relacionado a um padrão estético e social identitário, ao qual o indivíduo deve fazer tudo para alcança-lo. Numa perspectiva histórica Sant'anna afirma:

No final da década de 1930, a falta de beleza e a indisposição já são consideradas "curáveis". Tônicos e remédios para branquear o rosto, "desencardir" e limpar a pele começam a prescrever a prevenção dos males físicos e a afirmar que a beleza não é mais um dom e sim algo que se produz e que cada um pode criar. (grifos nossos SANT'ANNA,2002, p.6).

Até momento citado pela autora, o culto ao corpo não era visto como um bom comportamento social, o que estava também associado a uma moral católica sobre o corpo. Com o surgimento da indústria de beleza, o corpo deixa de ser apenas uma “casa” da alma, do espírito, segundo Sant'anna (2002), e passa a ter destaque na cultura, especialmente para as mulheres, quando ser bela torna-se uma obrigação. A partir de então, o corpo passa a ser um marcador cultural, sendo expandido a homens e crianças a busca por padrões sociais impostos para e sobre o corpo, e certa vaidade.

Dornelles (2010, p. 7) diz que “o corpo é o meio pelo qual se age sobre o mundo e nele incidem determinadas práticas. Essas práticas produzem um corpo de mulher, de homem, de menino ou de menina [...]". É comum então ver crianças cada vez mais cedo reproduzindo ideais e comportamentos considerados belos, adequados para seu gênero, e introduzidos pela publicidade infantil. Com relação a publicidade, Sabat (2001, p.16) afirma que: “A publicidade propõe representações de mulheres, de homens, de crianças [...] Ela constrói um tipo de sexualidade adequado a cada sexo, ao mesmo tempo em que tenta preservar essas sexualidades." Em relação as sexualidades, visualizamos nas vestimentas 
apresentadas pela indústria infantil, uma tendência, especialmente nas meninas, mas também nos meninos, ao enquadramento dentro de padrões vinculados a beleza.

O corpo é o primeiro lugar de experimentação e comunicação do indivíduo com o meio. $\mathrm{Na}$ infância, ele se manifesta antes da própria fala, é pelo corpo que a criança se faz entender e se comunica, por demonstrações físicas e expressões faciais. A medida que vai se desenvolvendo, a identidade social de cada pessoa começa a ser demarcada pelo corpo, por questões de gênero atribuídas, identidade, religião, disciplinamento do corpo, comportamentos psíquicos da criança, bem como outras questões de saúde, e alimentação.

Assim, não há como dissociar os corpos infantis sem problematizar quais as influências culturais trazidas pelos corpos em relação aos comportamentos de gênero socialmente atribuídos ao feminino e masculino, e como isto desencadeia em um disciplinamento, isto é, em formas de ser e de agir dos meninos e meninas que estão na educação infantil.

Segundo Guizzo, Beck e Felipe (2013) gênero, assim como infância e sexualidade, é um conceito provido de construções sociais, culturais e históricas. O que denota a compreensões de caráter provisório, podendo ser reconstruídas ou reconfiguradas de acordo com determinado contexto.

Exemplificando como se construiu o conceito de gênero, Meyer (2008):

[...] nós aprendemos a ser homens e mulheres desde o momento em que nascemos até o dia em que morremos e essa aprendizagem se processa em diversas instituições sociais, a começar pela família, passando pela escola, pela mídia, pelo grupo de amigos, pelo trabalho, etc. Mas significa mais ainda: como nós nascemos e vivemos em tempos e lugares específicos, gênero reforça a necessidade de se pensar que há muitas formas de sermos mulheres e homens, ao longo do tempo, ou no mesmo tempo histórico, nos diferentes grupos e segmentos sociais. O conceito de gênero também não se refere mais ao estudo da mulher, ele é um conceito que procura enfatizar a construção relacional e a organização social das diferenças entre os sexos, desestabilizando desta forma $\mathrm{o}$ determinismo biológico e econômico vigente, até então, em algumas das teorizações anteriores. (MEYER, 2008, p. 25 - grifos nossos).

De tal modo, as identidades de gênero são definidas por padrões e estereótipos considerados pertencentes a homens e mulheres, ligando as questões de gênero à sexualidade do indivíduo. Padrões que são reforçados a todos os momentos dentro da escola, por professores que acreditam que certas atitudes são aceitáveis para ser menino ou menina na sociedade, ou que mesmo sem perceber reafirmam por atitudes a segregação por gêneros. Pois segundo Buss-Simão (2013,p.7) "para os adultos, gênero é uma categoria útil para classificar, dividir, seriar, juntar as crianças, por isso passa a ser fundamental no âmbito das creches, pré-escolas e escolas, até mais que a estratificação social ou pertença racial." Raros são os movimentos contrários às definições culturais sobre homens e mulheres dentro da instituição, perceptível pela dificuldade em romper com determinadas acepções, pois estamos inseridos em uma sociedade ocidental, onde as feminilidades e as masculinidades se regulam o tempo todo pela definição de um outro. 
O enquadramento em determinado gênero, é atrelado à criança pequena desde seu nascimento por parte do contexto histórico e social que ela se encontra, segundo Argüello (2013, 118) "as representações masculinas (e as femininas) calcam marcas nos corpos, tanto nas manifestações quanto nas contestações que os sujeitos são obrigados a fazer.”. Estando a criança inserida na educação infantil, seja em creches, pré-escolas ou escolas, é fundamental que a instituição questione e problematize os artefatos culturais vinculados ao masculinos e femininos e apresentados pelas crianças neste espaço, visando a pluralidade de gêneros, raças, etnias, classes e sexualidade, contribuindo para a construção de uma sociedade mais igualitária, pois como ressalta Buss-Simão (2013) com relação a categoria de gênero:

Torna-se uma categoria profícua para ser analisada pelo ponto de vista das crianças, ou seja, ser analisada na dinâmica de como esse processo é vivido pelas crianças, quais elementos sociais e culturais marcam esse processo. Como as crianças se utilizam desses conhecimentos nas interações e relações sociais que estabelecem com seus pares e com os adultos em instituições de educação infantil.” (BUSS-SIMÃO, 2013, p.7)

Deste modo, a instituição deixa de ser mais um espaço com segregação de gênero e de sexualidade, e torna-se um local equânime nas relações de gênero.

\section{Quando rosa vira vermelho}

Esta categoria de análise é baseada na observação e registro de três situações ocorridas em sala de aula, onde os marcadores de gênero estavam presentes, e interferiram na proposta inicial da atividade. $O$ título escolhido "Quando rosa vira vermelho" faz uma alusão ao que ocorre nas cenas observadas, quando as crianças denominam a cor rosa como a cor vermelha.

\section{Atividade de desenho com giz branco em papel color set}

Durante a atividade, cujo objetivo foi explorar formas diferentes de desenho, proporcionando momentos de descobertas com o giz branco no papel colorido, as professoras pediram às crianças que sentassem nas cadeiras em volta das mesas, organizando-se em grupos com os colegas que quisessem. Estavam presentes quinze crianças, seis meninas e nove meninos. Foi explicado então ao grupo que naquele dia iriam desenhar com o giz branco, na folha colorida, questionando as crianças sobre o que elas achavam, se iria aparecer o desenho na folha ou não, em uma conversa como motivação prévia. Algumas responderam que sim, outras que não, e então iniciou-se a realização da atividade. Ao distribuir folhas coloridas, nos grupos que ficaram com formação mista, foi entregue a um menino, que vamos chamar de Martin, uma folha na cor rosa aleatoriamente, este ao receber a folha, disse: 
Mostrando aos colegas em seguida a folha recebida, e sorrindo. Então, uma menina, que vamos chamar de Carol, respondeu a ele:

- Este não é vermelho, é rosa de meninas! (CAROL, 4anos)

Ele então sentindo-se contrariado pela resposta da colega, afirmou a ela que a folha não era da cor rosa, porque rosa era de menina, e ele era menino, então não poderia usá-la, por isso a cor era vermelha. Carol rebateu afirmando a ele que sim, a folha era rosa de menina. Então, ele virou-se para professora e disse:

- Né que esse é vermelho Profe?(MARTIN, 4anos)

Ao receber a negativa da professora, ficou chateado e empurrou a folha, dizendo que então não ia desenhar nela. Então foi explicado a ele que não havia problema em desenhar naquela folha, que rosa não era uma cor de menino ou menina, era simplesmente uma cor, igual ao amarelo, ao vermelho, ao preto, ao verde, etc. Ainda assim, ele negou-se a completar a atividade, e demonstrou ficar chateado, por não ter concordado com ele, e ter lhe entregado aquela folha.

Pela observação do restante da tarde, foi perceptível a chateação por parte do menino com a professora envolvida, pois ele passou a solicitar exclusivamente a outra professora para qualquer situação, ignorando a presença daquela que interviu na situação no restante do dia. (atividade realizada em 21 de agosto de 2014).

\section{O Rosa de meninas}

A organização das crianças para a atividade foi semelhante à da primeira cena, isto é, com as crianças sentadas em grupos. O objetivo foi possibilitar a mistura de cores bem como o acesso a outros materiais para realização de exploração artística (pratos de papelão), para posterior criação de um chapéu com os materiais que foram pintados, incentivando a produção com materiais de sucata.

Cada grupo, recebeu um recipiente contendo as cores Laranja, Amarelo, Branco, Azul, Verde e Rosa, para pintura de pratos de papelão, que viriam a ser transformados em um chapéu para cada uma das crianças. As cores foram previamente selecionadas pelas professoras, pois na pintura do material de papelão, elas se destacavam melhor quando misturadas. Durante a separação dos grupos que foi feita pelas crianças, um deles foi composto apenas por meninos: William, Leonardo, Daniel e Martin. Foi decidido pelas docentes não interferir nesta situação, deixando o grupo organizado de tal maneira, mas habitualmente as crianças são misturadas quando ocorrem separações por gênero na organização das atividades. 
Foi solicitado que as crianças explorassem as cores, misturando elas durante a pintura, ao iniciar a atividade. No grupo formado somente por meninos, William, viu a cor rosa e exclamou:

- Olha Vermelho, minha cor favorita! (WILLIAM, 4 anos)

Ao ouvir de outro menino, Leonardo, que aquela cor não era vermelha, era "rosa de meninas" largou o pote e parou de usar em sua pintura, respondendo que então ele não queria. Daniel, outro menino do grupo chamou uma das professoras, solicitando que ela retirasse aquela tinta do grupo deles. Que o questinou:

$$
\text { - Por que? (PROFESSORA) }
$$

Ele respondeu:

-Porque nós somos meninos e não queremos esta cor de menininha, só gostamos de vermelho. (DANIEL, 3 anos)

Argumentando que não havia a cor vermelha disponível ali, que realmente como ele disse, aquela cor era a rosa, mas que ele poderia explicar porque era de menina.Ele respondeu:

- Não sei, mas esta cor não é para nós!(DANIEL, 3 anos)

Foi explicado ao grupo que não seria retirado o pote cor de rosa da mesa, porque aquela era uma cor como as outras na sala, e que meninos e meninas poderiam utilizar. Ainda, foi trabalhado a técnica de mistura das cores na atividade, para que eles verificassem que ao misturar com outras tintas na pintura (que era a proposta explicada a eles inicialmente) as cores mudavam de cor, não só rosa, mas as outras que estavam ali. No entanto ao final da atividade, nenhum deles havia utilizado a tinta rosa na sua produção. (Atividade realizada em 23 de setembro de 2014).

\section{Atividade com anilina (Fabricação de meleca)}

$\mathrm{Na}$ atividade, foram utilizados amido de milho, água e anilina colorida para fabricar a meleca originada da mistura com os três ingredientes com o objetivo de brincar com texturas diferentes, explorando o tato e a curiosidade das crianças. Neste dia estavam presentes dezoito crianças, sete meninas e onze meninos. As cores vermelha e verde da anilina, foram selecionadas conforme o estoque na instituição. Foi a segunda vez esta atividade estava sendo realizada na turma.

A atividade foi realizada em uma sala da instituição denominada multiatividades, a qual possui um espaço amplo sem mesas e cadeiras, dando mais mobilidade as crianças durante a proposta. Com um papel pardo no chão as crianças foram convidadas para se colocarem em seu em torno. Uma das professoras foi misturando os ingredientes junto com a turma. Durante a mistura, um dos meninos, Paulo 
que estava ao lado da outra professora, ao ver a cor rosa resultante do inicio da mistura entre o vermelho e o amido de milho, disse que não iria brincar com a meleca rosa, que rosa era coisa de menininhas.

A expressão em sua face aparentava angústia e medo, pela cor da meleca. Não foi feito nenhum comentário sobre a fala de Paulo, pelas professoras, que apenas solicitaram que as crianças continuassem atentas ao processo. Ao final a mistura da primeira meleca, atingiu a tonalidade vermelha. No entanto, curiosamente, Paulo, pouco se envolveu durante a atividade, ficando um pouco a parte na interação com o material, e comentando com outros meninos que aquela meleca "teve cor rosa, eu vi." (PAULO, 3 anos)

Quando foi realizada a segunda mistura, desta vez da cor verde, ele interagiu mais com o material, aproximando-se do papel e mexendo no recipiente da meleca. (Atividade realizada em 10 de outubro de 2014).

Nas três situações anteriormente descritas, as crianças eram convidadas a exploração de diferentes materiais com tinta, anilina comestível e papéis de diversas cores. Durante as cenas, algumas falas das crianças denotam a forte presença de marcadores de gênero nos meninos, e também nas meninas da turma, pelo reforço de estereótipos atrelados ao masculino.

Os meninos, como ressalta Louro (2010) são "alvo de uma vigilância muito mais intensa" (p.27), a regulação social de gênero neles aparece com bastante frequência na turma, demonstrando a realidade cultural que ainda vivemos, de um maior controle sobre ser menino. Eles não quiseram participar das atividades ou realiza-las plenamente, quando apareciam marcadores de gênero atrelados socialmente ao feminino, por que tais marcadores como dizem as crianças da turma são "de meninas, menininhas". É interessante registrar aqui que o diminutivo usado, muitas vezes acompanhado de expressões faciais que demonstram desprezo, são indicativos nas crianças que aspectos que, se relacionam ao feminino, são depreciativos quando usados pelo masculino. Para os meninos da turma do Maternal II, o que pertence a uma identificação vinculada às feminilidades é o que eles não querem/podem ter, como Sabat (2001) afirma:

[...] há um padrão construído que envolve determinados tipos de comportamentos, de sentimentos, de interesses. São todos significantes construídos junto a significados que constituem em determinado momento histórico o que é percebido como masculinidade, ou melhor, como $a$ masculinidade, que se opõe à feminilidade e que se sobrepõe a outras formas de masculinidade. (SABAT, 2001, p.10)

É pertinente destacar que além disso, compreendemos pelas observações feitas, que os meninos demonstram buscar no vermelho o respaldo para utilização daquilo que eles já internalizaram como não ser de seu uso, expressado pela cor rosa. Isto é comprovado na insistência em solicitar à professora que afirme a cor como vermelha, para que assim eles sintam-se autorizados a utilizá-la. Quando ela os contrapõe com a negativa, eles ou não participam da atividade, ou a ignoram durante o dia, ou pouco envolvem-se com o material. 
Felipe (2001, p.65) pontua que: "cabe também às educadoras e educadores, diluir algumas barreiras ao que seja apropriado para meninas e meninos". A professora age de forma pertinente, ao possibilitar que estas discussões sejam feitas na turma por intermédio da atividade, pois quando elas ficam evidentes na rotina das crianças, há um demonstrativo da necessidade de trabalhar sobre tais temáticas com a turma. A professora que demonstra um olhar diferente às questões de gênero que a criança traz para a educação infantil, consegue gerar novos subsídios para que ela construa outras referências ao que se refere as identidades de gênero.

Então temos nas cenas a conexão entre as questões de gênero e o pedagógico, quando se misturam ao que foi proposto ${ }^{5}$, e possibilitam novas articulações durante a atividade. Estas conexões aparecem por parte das crianças quando elas reafirmam um posicionamento ligado a determinado gênero que lhes foi atribuído desde cedo.

A interferência de gênero na atividade, permite outro viés para a proposta inicial, indo além da exploração, pintura, e criação com os materiais, possibilitando com que as discussões auxiliem as crianças no processo de construção e pluralização sobre gêneros, relativizando o que é socialmente atribuído masculino e feminino.

É necessário, que se problematize as questões das crianças, dando sentido ao que elas destacam nas situações, oportunizando assim, embora que, minimamente, novas formas de se pensar e encarar as feminilidades e masculinidades cultivadas em nossa cultura, pois citando Louro (2010) os gêneros são constituídos sobre corpos sexuados, numa perspectiva sócio-histórica. Finalmente, se tratando de educadores, é necessário um aparato de subsídios para que nosso trabalho com as crianças dê condições favoráveis ao respeito com o outro, penso que isto é fundamental em uma sociedade diversa como a nossa, que as diferenças não acabem sendo transformadas em desigualdades.

\section{Borramentos de fronteiras de gênero - as fantasias}

Nesta categoria foi selecionada a seguinte situação que apresenta um contraponto às demais cenas da pesquisa, e por este motivo denominada - borramentos de fronteiras de gênero:

Fantasias com tecidos, retalhos, roupas e luvas.

\footnotetext{
${ }^{5}$ Como exemplo de atividades onde as questões de gênero se conectam com o ensino das artes, tem um artigo publicado em 2002 (Educar O olhar, conspirar pelo poder: gênero e criação artística), pela Professora Doutora em Bellas Artes da Universidade Complutense de Madri, Marián López Fernandez Cao, que apresenta situações de uma aula de artes em que frases sem definição de sexo eram ditas aos alunos para que eles as reproduzissem, possibilitando a educação do olhar das variáveis de gênero na criação artística. Ver em: LF CAO, M. (2002) "Educar la mirada; género y REPRESENTACION del mundo "conferencia pronunciada en el Congreso Internacional Educar para Uma Sociedade Inclusiva. Lisboa, 2000, Ministerio de Educación de Portugal. Actas del Congreso.
} 
No início do ano, foi solicitado aos pais da turma na lista de materiais que não trouxessem fantasias demarcadas, tais como de super-heróis, princesas, bailarinas e etc. No entanto, eles trouxeram somente estas fantasias. Em alguns momentos ao longo do ano, elas que foram usadas e solicitadas pelas crianças da turma durante a rotina. Notando que eles gostavam bastante dos momentos de fantasia, foi proposto pelas professoras um momento com tecidos, retalhos, roupas e outros artefatos, de diversas cores - incluindo rosa e azul, para que eles criassem as suas fantasias e, com isso, estimular a criatividade das crianças, fazendo com que elas pensem em outras fantasias além das estereotipadas que estão na sala.. A intenção era tentar desvincular um pouco as crianças, durante a atividade, dos personagens que elas estavam acostumadas com as outras fantasias, buscando relativizar assim o que é para menino ou menina.

Tal atividade foi realizada no espaço mais amplo da sala, especificamente no tapete da turma. Ao propor a atividade, foi explicado para as crianças que esta seria brincar de fantasia, com os tecidos trazidos em uma bolsa mágica. As crianças exploraram sem privações, meninos colocaram luvas longas de produções festivas socialmente atribuídas ao feminino, amarraram lenços rosas ao corpo, fingindo serem os super-heróis, mesmo com a presença da cor rosa. As meninas pegaram os retalhos azuis e fizeram vestidos de princesas, pedindo as professoras que fizessem coroas para elas, com papéis da sala

Durante a atividade, as crianças iam até o espelho, olhavam-se, e agiam representando papéis conforme denominando na brincadeira da fantasia: Martin, dizia ser o Batman com a máscara de morcego, ao colocar um lenço amarrado no rosto. Nas meninas, Jéssica, enrolada em um pano azul, desfilava pelo tapete dizendo ser a Cinderela. Ao fim da atividade, foi observado que todas as crianças vestiram alguma peça trazida para a sala, atingindo o objetivo pretendido nesta proposta.(Atividade realizada em 28 de agosto de 2014).

Elencamos então para esta análise, alguns pontos a refletir sobre a cena: na brincadeira com fantasia a criança expressa seus sentimentos internalizados, envolvendo-se com os materiais ofertados. $\mathrm{O}$ espaço livre também contribui, ampliando as possibilidades de movimentação para as crianças realizarem a atividade, ofertando mais autonomia na experimentação dos tecidos e objetos. Louro (2010,p.79) diz que "se constrói na escola uma série de situações que representariam um "cruzamento de fronteiras", ou seja, situações em que as fronteiras ou os limites entre os gêneros são atravessados", o que fica evidenciado na cena, quando a vivência da fantasia pelas crianças as auxilia no borramento das fronteiras de gênero, utilizando em suas brincadeiras, cores como rosa e azul, e chapéus e luvas dadas como tipicamente femininas. Ainda, com relação ao cruzamento das fronteiras de gênero, Louro (2010) afirma:

No terreno das relações de gênero, é possível observar muitas vezes essa característica mais "frágil" ou frouxa", que permite, àqueles/as que se vêem questionados numa situação de contato ou cruzamento das fronteiras, o uso da justificativa: "nós só estávamos brincando. (LOURO, 2010, p.79)

De modo que o uso da fantasia na cena empodera a brincadeira para o cruzamento das fronteiras de gênero, mas não só, amplia os discursos culturais ao qual o sujeito está imerso em si próprio, dentro da 
viagem conforme Louro (2004,p.13)_a qual todos estamos inseridos e criando: “ um processo que, ao invés de cumulativo e linear, caracteriza-se por constantes desvios e retornos sobre si mesmo", a medida que " gênero e a sexualidade guardam a inconstância de tudo que é histórico e cultural: por isso, às vezes, escapam e deslizam.” (Louro, 2004, p.17)

Para Santos (2001) a brincadeira, como na cena da fantasia, é denominada como o jogo espontâneo infantil. Partilhando de suas afirmações:

Podemos então definir [...] como um espaço de experiência e liberdade de criação no qual as crianças expressam suas emoções, sensações e pensamentos sobre o mundo e também um espaço de interação consigo mesmo e com os outros. (SANTOS, 2001, p.89).

Temos então, durante a atividade na turma, uma fluidez nas fronteiras de gênero, pois tanto os meninos quanto as meninas do grupo conseguem recriar significados culturais atribuídos as masculinidades e feminilidades. Pode se dizer ainda, que as desconstruções são necessárias na rotina, e devem ser ofertadas por profissionais da educação, pois a escola é o espaço de se oportunizar outras referências para o indivíduo, com relação as definições sociais do meio ao qual ele pertence. No que se refere às questões de corpo e gênero, a escola pode oportunizar outras experiências com relação às temáticas, por intervenções pertinentes da professora que tem contato mais direto com a turma, assim é possível conjecturar sobre as reproduções culturais com o grupo.

Segundo Santos (2001) é durante o faz-de-conta que a criança vai executar curiosidades de forma mais confortável que por algum motivo não lhe são proporcionadas em outros momentos. Ainda, a proposta da fantasia que inicialmente foi sugerida pela adulta, reveste-se na execução com novas determinações, novas regras que as próprias crianças estabelecem, exercitando sua criatividade em atribuir outros significados aos objetos e suas representações.

As propostas que vinculam alguns marcadores de gênero, e discutem sobre eles, auxiliam as professoras a alcançarem um contraponto à fixidez da turma, nas masculinidades e feminilidades. Nas três primeiras cenas, poderia se propor às crianças uma troca das cores pela mistura, mostrando por exemplo, que a rosa é também a vermelha misturada com a branca, a azul pode ser verde quando misturado ao amarelo, ou ainda ser mais claro, quando misturado ao branco, e assim por diante. A partir disso, demonstra-se que as crianças não só nos momentos de faz-de-conta, ou de fantasia, as crianças podem vivenciar de forma distinta as regras culturais, mas também em outros momentos da rotina.

\section{APONTAMENTOS SOBRE O TRABALHO DOCENTE}


O professor é um organizador de aprendizagens [...] Organizador do ponto de vista da organização da escola, do ponto de vista de uma organização mais ampla, que é a organização da turma ou da sala de aula. Há aqui, portanto, uma dimensão da organização das aprendizagens, do que eu designo, a organização do trabalho escolar e esta organização do trabalho escolar é mais do que o simples trabalho pedagógico, é mais do que o simples trabalho do ensino, é qualquer coisa que vai além destas dimensões, e estas competências de organização são absolutamente essenciais para um professor. (NÓVOA, 2001, p.2.)

Nas cenas analisadas para a pesquisa, foi possível identificar que o rompimento das fronteiras de gênero por parte dos meninos e meninas do grupo nem sempre ocorre, porém há uma organização da atividade, que incorpora marcadores atrelados a masculinidades e feminilidades como a cor rosa, dando subsídios para que, como afirma o autor, as aprendizagens direcionem-se para além das dimensões atribuídas ao ensino.

As questões de corpo e gênero na educação infantil são temáticas relevantes que exigem por parte da professora um aparato teórico, e também uma visão histórico - cultural do contexto de cada grupo, para serem inseridas no planejamento docente, e devidamente trabalhadas, conforme se fizer necessário na turma.

No maternal II - turma na qual esta pesquisa foi realizada - o corpo e as questões de gênero eram centralizadas pelas crianças durante as atividades, incitando a discussão sobre as temáticas. Refletindo sobre a ação pedagógica das cenas analisadas, pontuamos que posterior a elas, foi debatido individualmente sobre as questões de gênero nas situações ocorridas. E se procurou, à medida que necessário, inserir de forma intencional os marcadores de gênero relacionados a cores e objetos nas atividades, como relatado na cena "o rosa de meninas" e também na cena "fantasias, retalhos, roupas e luvas".

Tal feito, exemplifica para futuras atuações, que o professor deve planejar levando em conta que o espaço da educação infantil não está alheio ao que acontece no externo, mas justamente, será palco para discussões e representações do que as crianças aprendem fora dali, conectando as vivências culturais com o pedagógico.

Nesta perspectiva, refletindo sobre o percurso percorrido, apontamos que ele teve o intuito de articular a educação infantil, o corpo e o gênero na infância, com situações observadas dentro de uma turma de Maternal II, a fim de construir novos e desembaraçar velhos significados para as questões de gênero na educação infantil.

Durante os estudos realizados na pesquisa, alguns subsídios foram construídos, possibilitando com que atualmente eu consiga utilizá-los em situações práticas da sala de aula quando questões de gênero são exploradas na rotina. Parafraseando Louro (2010), quando estamos atentas aos pequenos indícios, percebemos que nem o tempo e espaços na escola são distribuídos ou concebidos do mesmo modo por todas as pessoas. 
O intuito da pesquisa foi o de promover a reflexão por intermédio das análises sobre as questões de corpo e gênero na Educação Infantil que, a meu ver, são importantes de serem debatidas em todos os âmbitos e profissionais da educação. Felipe (2001, p.65) afirma: "[...] as expectativas que temos em relação a homens e mulheres, meninos e meninas são construídas numa determinada cultura e num determinado tempo histórico", isso quer dizer que em diferentes tempos e culturas, teremos diferentes expectativas sociais sobre o ser menino e menina, que serão trazidas pelas crianças nas diversas situações da rotina na escola, e que teremos enquanto professoras que aprender a problematizar em nosso trabalho, visando uma sociedade mais igualitária, e uma prática docente coerente.

Contudo assim com o intuito da pesquisa não visava ditar fórmulas, este artigo tampouco, mas sim que sirva como ferramenta auxiliar para outras profissionais, a refletir sobre situações onde o corpo e gênero se ressaltam na educação infantil. Acredito que a longo prazo, os marcadores de gênero podem vir a ser flexibilizados na nossa cultura, através de pertinentes intervenções desde a educação infantil, contribuindo para que as experiências das crianças sejam cada vez mais enriquecedoras e transformadoras, visando uma sociedade menos sexista. 


\section{Referências}

ARGÜELLO, Zandra Elisa. Contos a favor da equidade de gênero. In: FELIPE, Jane; GUIZZO, Bianca Salazar; BECK, Dinah Quesada (org.). Infâncias, gênero e sexualidade nas tramas da cultura e da educação. Canoas: ED.ULBRA, 2013. p. 109 - 124.

BRASIL. Senado Federal. Lei de Diretrizes e Bases da Educação Nacional: $\mathrm{n}^{\mathbf{0}}$ Lei $\mathrm{n}^{\mathbf{0}} \mathbf{1 2 . 7 9 6 .}$ Brasília : 2013. Disponível em: http://www.cpt.com.br/ldb/dos-niveis-e-das-modalidades-de-educacaoe-ensino. Acesso 10 de agosto de 2014.

BARBOSA, Maria Carmem Silveira; HORN, Maria da Graça Souza.Projetos pedagógicos na Educação Infantil. Porto Alegre: Artmed, 2008.

BUJES, Maria Isabel Edelweiss. Escola infantil: Pra que te Quero?. In: CRAIDY, C.; KAERCHER, G. E. (org.). Educação Infantil - pra que te quero? São Paulo: Artmed, 2001. P - 13 -22.

BUSS-SIMÃO, Márcia. Gênero como possibilidade ou limite da ação social: um olhar sobre a perspectiva de crianças pequenas em um contexto de educação infantil. Revista Brasileira de Educação. v.18, n.35, 939-961, 2013.

CERISARA, A. B. Educar e cuidar: por onde anda a educação infantil? Perspectiva. Florianópolis, v. 17, n. especial, p.11-21, jul./dez. 1999

CORSARO, William. Reprodução interpretativa da cultura de pares. In: CARVALHO, Ana Maria Almeida.; MÜLLER, Fernanda. (org.). Teoria e Prática na pesquisa com crianças: diálogos com William Corsaro. São Paulo: Cortez, 2009.

DIRETRIZES Curriculares Nacionais Gerais da Educação Básica / Brasília: MEC, SEB, DICEI, 2013.562p

DORNELES, Leni Vieira. Sobre Meninas no Papel: inocentes erotizadas? As meninas hoje. Revista Educação e Realidade. Porto Alegre, v. 35, n. 3, p. 175-192, set./dez., 2010.

FELIPE, Jane. Sexualidade, gênero e novas configurações familiares: algumas implicações para a Educação Infantil. In: CRAIDY, Carmem; KAERCHER, Gládis E. (orgs.). Educação infantil: para que te quero? Porto Alegre: Artmed, 2001. p.61-66.

GOELNNER, Silvana. A produção cultural do corpo. In LOURO, G., NECKEL, J. E GOELLNER, S. (orgs.) Corpo, gênero e sexualidade. Um debate contemporâneo na Educação.Petrópolis: Vozes, 2003, p.28-40.

GUIZZO, Bianca Salazar; FELIPE, Jane; BECK, Dinah Quesada. Infâncias, gênero e sexualidade: articulações possíveis. In: FELIPE, Jane; GUIZZO, Bianca Salazar; BECK, Dinah Quesada (org.). Infâncias, gênero e sexualidade nas tramas da cultura e da educação. Canoas: ED.ULBRA, 2013. p. $17-28$.

HALL, Stuart. Quem precisa de identidade? In: SILVA, Tomaz Tadeu. Identidade e diferença: a perspectiva dos estudos culturais. $9^{\circ}$ ed. Petropólis, RJ: Vozes, 2000, p.103-133.

LOURO. Guacira Lopes. Um corpo estranho. Belo Horizonte: Autência, 2004.

Gênero, sexualidade e educação: Uma perspectiva pós-estruturalista / 11 ed. Petrópolis, RJ: Vozes, 2010. 
LÜDKE, Menga; ANDRÉ, Marli. Pesquisa em educação: abordagens qualitativas. São Paulo: EPU, 1986.

MEYER, Dagmar. Gênero, Sexualidade e Currículo. PGM2. In.: MEC; Salto para o futuro. Educação para Igualdade de gênero. Ano XVIII. Boletim 26. Nov/2008. Disponível em: http://tvbrasil.org.br/fotos/salto/series/163222Edu_igualdade_gen.pdf Acesso em 28/10/2014

MEYER, Dagmar e SOARES, Rosangela de Fátima Rodrigues. Corpo, Gênero e Sexualidade nas práticas escolares: um início de reflexão. In: MEYER. Dagmar Ester; SOARES, Rosangela de Fátima Rodrigues (orgs.). Corpo, Gênero e Sexualidade. 3. ed. Porto Alegre: Mediação, 2013. p. 5 - 16.

MINAYO, Maria Cecilia de Souza. O desafio do conhecimento. São Paulo: Hucitec,1999.

NÓVOA, Antônio. O Professor Pesquisador e Reflexivo: entrevista [13 set. de 2001]. p. 1- 6 Disponível<http://www.vdl.ufc.br/solar/aula_link/llpt/A_a_H/didatica_I/aula_04/imagens/03/profes sor_pesquisador_reflexivo.pdf>. Acesso em 04 maio 2016

SABAT, Ruth. Pedagogia cultural, gênero e sexualidade. Revista Estudos Feministas. Florianópolis (SC): v.09, n.01, p.09 - 21, 2001.

SANT'ANNA, Denise Bernuzzi de. Transformações do corpo - controle de si e uso dos prazeres. In: RAGO, M.; ORLANDI, L.B.L; VEIGA NETO, A. (org). In: Imagens de Foucault e Deleuze: ressonâncias nietzschianas. Rio de Janeiro: DP\&A, 2002. p. 99-110.

SANTOS, Vera Lúcia Bertoni dos Santos. Promovendo o Desenvolvimento do Faz-de-Conta na Educação Infantil. In: CRAIDY, C.; KAERCHER, G. E. (org.). Educação Infantil - pra que te quero? São Paulo: 